\title{
EDITORIAL
}

\section{Infección por SARS-CoV-2: pandemia que estimula el conocimiento y su relación con las alteraciones endocrinas}

$\mathrm{E}$ l proceso de publicaciones en nuestra revista ha tenido continuidad trimestral desde sus inicios, con 3 separatas adicionales; sin embargo, esta es la primera separata dedicada a unas minirrevisiones profundas de un tema actual y cambiante minuto a minuto, que presenta incertidumbres de conocimiento y avances vertiginosos en las ciencias básicas, moleculares y clínicas, con los que se busca lograr salvar vidas en este brote actual de infección por coronavirus. Deseamos tener evidencias suficientes para avanzar en el proceso de cómo los profesionales que intervenimos y de salud pública podemos prevenir y manejar las epidemias. Por esto, es necesario brindar información procesable lo antes posible, como se aporta en esta edición de la revista. Examinamos rápidamente los manuscritos realizados por nuestros colegas endocrinólogos y colaboradores, para que pudiésemos tener el conocimiento al día; es decir, la mejor información disponible de manera transparente y expedita de esta nueva situación pandémica en el mundo, bajo la premisa de que condiciones como esta ameritan un enfoque evaluativo diferente.

Las enfermedades infecciosas continúan perturbando y amenazando a las poblaciones humanas, con registros históricos de pandemias descritas desde la peste antonina (165-180 d. C.), desencadenada por el Imperio Romano a su regreso del Medio Oriente y que causó 5 millones de muertes, continuando con la plaga de Justiniano (541-542), que dejó de 30 a 50 millones de muertes; la viruela japonesa (735-737), con 1 millón de muertes; la peste negra (1347-1351), iniciada en Asia Central y que causó 200 millones de muertes; la viruela (1520), introducida en México, con 56 millones de muertes; la peste bubónica en Inglaterra (1600), que dejó 3 millones de muertes; la peste rusa, con 600.000 muertes; el cólera (1817-1923) en Asia, con 1 millón de muertes; la tercera peste bubónica en China (1855), que produjo 12 millones de muertes; la fiebre amarilla (fines de 1800), con 150.000 muertes entre América y Europa; la gripe española (1918-1919), que causó 40-50 millones de muertes; la gripe rusa (1889-1890), con 1 millón de muertes; la gripe asiática (1957-1958), que inició en Guizhou, China, y dejó 1,1 millón de muertes; la gripe de Hong Kong (1968-1970), con 1 millón de muertes; la infección por VIH (1981-actualmente), iniciada en África Central, con 25 a 30 millones de muertes; el SARS (2002-2003), que se originó en el sur de China, con 8098 personas infectadas y que provocó 770 muertes causadas por un coronavirus (el SARS-CoV); la gripe porcina (2009-2010), iniciada en el centro de México y que ocasionó 200.000 muertes; el MERS (2012-actualmente), que reportó el primer caso en Arabia, con 850 muertes ocasionadas por un coronavirus (el MERS-CoV); el Ébola (2014-2016), iniciada en Guinea, con 11.300 muertes y letalidad de hospitalizados del $57 \%{ }^{(1,2)}$; hasta llegar a la actual pandemia iniciada en Wuhan-Hubei, provincia de China, diseminada en todo el globo terrestre y desencadenada por un patógeno emergente: el coronavirus COVID-19 o SARS-CoV-2, que ha contagiado 4.891 .785 casos, con 324.496 muertes a la fecha de este escrito ${ }^{(3)}$.

Estamos afrontando una pandemia en sociedades caracterizadas por gran desigualdad, hacinamiento, contacto humanoanimal, tecnología avanzada, redes sociales sin límite y viajes globales, situaciones que han contribuido a la expansión tanto de la enfermedad como del conocimiento mundial. Como lo escribió el Dr. Charles E Rosenberg: "Las epidemias comienzan en un momento en el tiempo, avanzan en un escenario limitado en espacio y duración, siguen una línea argumental de creciente tensión reveladora, avanzan hacia una crisis de carácter individual y colectivo, y luego derivan hacia el cierre" ${ }^{(4)}$.

El mundo es un lugar diferente de lo que era en 1918 o en las épocas cuando ocurrieron las pandemias que ha padecido la humanidad. Actualmente, disponemos de más tecnología para realizar investigación y herramientas necesarias para desarrollar medidas y tomar decisiones con mejor fundamento y solidez.

El brote de la COVID-19 nos recuerda que hay un desafío continuo impuesto por los patógenos nuevos o reemergentes, mutados o no; además, nos invita a estar atentos mediante la vigilancia constante, la capacidad de diagnóstico inmediato y una investigación sólida que nos permita entender el comportamiento de estos nuevos microorganismos y ser capaces de tomar decisiones efectivas para evitar las diseminaciones y la mortalidad y lograr disminuir las consecuencias del deterioro socioeconómico global. Para sobrepasar esta crisis sistémica, como lo expresa el Dr. Ha-Joon Chang, de la Universidad de Cambridge, se requieren altos niveles de confianza en el estado, basados en un historial de políticas económicas y efectivas de protección a los más débiles, como también enfoques más colectivos ${ }^{(5)}$. 
En esta pandemia, se ha logrado identificar comorbilidades que hacen más susceptibles al individuo o riesgos mayores de complicación ante la infección por el coronavirus, y los estudios están avanzando para comprender y delinear los factores de progresión de la enfermedad. Es así como se sugiere que la diabetes mellitus, la obesidad, la hipertensión arterial, la enfermedad cardiovascular y pulmonar conllevan un mayor riesgo de presentación grave de infección por COVID-19 o de fallecer a causa de esta $^{(6)}$. Las investigaciones relacionan dos proteínas receptoras del coronavirus: la enzima convertidora de la angiotensina 2 (ECA-2) y la dipeptidil-peptidasa-4 (DPP4), que son transductores de las señales metabólicas y vías que regulan la inflamación ${ }^{(7)}$. Se combate no solo a una enfermedad altamente contagiosa, con una respuesta inflamatoria marcada, conocida como tormenta de citocinas, sino también a enfermedades no trasmisibles que empeoran el pronóstico de la infección.

Pretender que en los manuscritos de esta publicación estén todos los registros y se abarque la revisión de las miles de publicaciones, como nunca se había hecho en el mundo sobre un mismo tema en tan corto tiempo, es ambicioso; sin embargo, procuramos entender y explicar, con los datos que se tienen hasta la fecha, la epidemiología de la COVID-19 en el mundo y en nuestro país, revisando el mecanismo de respuesta inmunológica, el comportamiento de este virus cuando interactúa con pacientes que padecen enfermedades crónicas, como diabetes mellitus, obesidad, malnutrición, patologías tiroideas y suprarrenales, y el comportamiento de la COVID-19 en la salud reproductiva, la inmunomodulación por vitaminas y antioxidantes, así como las circunstancias ambientales que puedan estar influyendo en la pandemia.

Estamos enfocados en la comprensión de esta nueva infección y en avanzar rápidamente en el conocimiento de las pruebas diagnósticas, la fisiopatología de la enfermedad, el tratamiento y las vacunas con innovación y desarrollo, que permita llegar a la declinación de esta infestación, que tantas vidas está cobrando en el mundo.

\section{Luz Ángela Casas Figueroa, MD}

Medicina Interna, Endocrinología. FACE.

Jefe, Servicio de Endocrinología FVL.

Docente, Universidad ICESI. Miembro Honorario, Asociación Colombiana de Endocrinología (ACE).

Expresidenta, ACE. Expresidenta, Capítulo Colombia, AACE.

Miembro, Comité Editorial, Revista Colombiana de Endocrinología, Diabetes y Metabolismo.

\section{Referencias}

1. Walsh B. Covid-19: The history of pandemics [Internet]. Disponible en: https://bbc.in/3cayDMW.

2. World Health Organization. Emergencies [Internet]. Disponible en: https://bit.ly/2TQghKN.

3. European Centre for Disease Prevention and Control. COVID-19 situation update worldwide [Internet]. Disponible en: https://bit.ly/3gzy6Hs.

4. Rosenberg C. What is an epidemic? AIDS in Historical Perspective. Daedalus. 1989;118(2):1-17.

5. Chang HJ. Interview on the COVID-19 crisis in 2 parts in the Korean newspaper, Hankyoreh [Internet]. Disponible en: https://bit.ly/2XyBf1K.

6. Zheng Z, Peng F, Xu B, Zhao J, Liu H, Peng J, et al. Risk factors of critical and mortal COVID-19 cases: A systematic literature review and meta-analysis. J Infect. 2020;S0163-4453(20)30234-6. doi: 10.1016/j.jinf.2020.04.021.

7. Drucker D. Coronavirus infections and type 2 diabetes-shared pathways with therapeutic implications. Endocr Rev. 2020;41(3):bnaa011. doi: 10.1210/endrev/ bnaa011. 